\title{
Assessing The Impact Of Virtual Reality-Based Training On Health And Safety Issues In The Mining Industry
}

\author{
Shiva Pedram ${ }^{A^{*}}$ \\ Pascal Perez ${ }^{\mathrm{A}}$ \\ Bruce Dowsett ${ }^{\mathrm{B}}$
}

\begin{abstract}
Best practice in the mining industry includes extensive initial and professional training for staff involved in field operations. Whereas changes in mining technology and operations accelerate to improve productivity, health, and safety standards have to be continuously evaluated and improved, putting more pressure on training deliveries. Borrowing from Defence and Airspace industries, training in the mining industry is increasingly relying on immersive virtual reality to simulate complex operations and procedures in potentially dangerous environments. Coal Services Pty Ltd is at the forefront of modern training facilities in Australia. This paper presents a qualitative and quantitative research framework designed to analyse the impact of past and current training sessions on staff's ability to better perform their tasks, overall safety standards, and mine productivity. Interviews with trainees, trainers, and managers are used alongside session recordings to qualitatively evaluate levels of knowledge transfer and aptitudes to perform in a real environment. Then, a cost-benefit analysis is used to evaluate the added-value of virtual realitybased on technological and operational costs weighed against overall productivity of the mine being negatively affected by any safety issue.
\end{abstract}

Key words: Simulation; Modelling; Virtual Environment; Mining Industry; Safety; Highly reliable organisation.

\section{Introduction}

A number of hazard industries have been trying to create the organisational and safety culture at their sites to transform the organisation into a highly reliable organisation. Highly reliable organisations (HRO) have been defined as organisations which are operating in hazardous condition but manage to almost sustain error-free performance; in such organisations the consequence of any error could be disastrous. There is abundant literature discussing the characteristics of HRO, key features that need to be adopted to create HRO or ways of controlling risks in hazards organisations but there is not much about methods of creating a HROs. We believe that Interactive virtual reality training environments can facilitate this transformation process for mining industry where it can change the hazardous organisation in to the HRO. There is an abundant literature on research dedicated to Interactive Virtual Reality (IVR) environments ${ }^{1-5}$, IVR-based teaching and training programmes ${ }^{6-8}$ or their application to

\footnotetext{
${ }^{\text {A }}$ SMART Infrastructure Facility, University of Wollongong, NSW

${ }^{\text {B }}$ Coal Services Pty Ltd, Argenton, NSW

*Corresponding author: Shiva Pedram sp185@uowmail.edu.au

http://dx.doi.org/10.14453/isngi2013.proc.36
} 
different industries ${ }^{9-14}$ Literature investigating and evaluating the impact of IVR-based training programs on safety and productivity records is far less abundant. In order to evaluate the impact of IVR on creating HRO and substantially training delivery, improvement to safety records and overall impact on productivity, it is necessary to access and analyse data from past and current training programs, along with feedback from trainees, trainers, and various managerial levels. These data need to be processed within a formal analytical framework that can incorporate qualitative and quantitative data, microscale (training session) to macroscale (corporate) levels.

\section{Mine and Safety}

There are two major thoughts that trying to explain accidents in complex, high hazard organisations: Normal Accident Theory (NAT) and High Reliability Organisation Theory (HROT). Normal accident theory was initiated by Charles Perrow ${ }^{15}$ and its main focus was on the concept that accidents are unavoidable in complex organisations that operate in high-risk and technology situations. He believes that because of the two main characteristics of these sorts of organisations, tight coupling, and interactive complexity, failure occurs. On the other hand Leveson, et al. ${ }^{16}$ argued that Perrow's categorising of industries in 'high risk' and 'low risk' category does not precisely reveal the accident rates and also theory offers a pessimistic view about accidents in complex systems and fails to suggest how the risk of accidents may be reduced $^{17}$ This criticism has been addressed by HRO which emphasise on understanding that under some conditions complex systems do not fail. HRO researchers argue that accidents in complex systems and hazardous organisations are not unavoidable because there are processes in place that allow high hazard organisations to efficiently prevent and avoid catastrophic errors helping them to attain a consistent record of safety over long time periods ${ }^{18-19}$

The mining industry faces both needs for high performance productivity and for drastic safety standards in the most hazardous working environments. Henceforth, it seems natural that the American Mine Safety and Health Administration (MSHA) asked the National Institute for Occupational Safety and Health (NIOSH) to explore and implement the use of IVR technology to develop training programs for open-cut or underground mining about hazard recognition, evacuation ways, and processes ${ }^{11}$. Likewise, South Africa started using IVR-based training programs in order to improve alarming workplace safety statistics. The South African Mine Health and Safety Authority (MHSA) started developing training environments as realistic and interactive as possible. Different technologies like joysticks, data gloves, or head-mounted displays were used to enhance trainee's immersion ${ }^{20}$. Open-cut or underground mining simulators provide safe, replicable, and cost-effective environments for miners to be trained and for engineers and managers to test different assumptions, strategies, and scenario outcomes. Henceforth, IVR-based training has the potential not only to improve workplace safety conditions, but also to contribute to a more effective management, more sustainable production, and, finally, more profitable industry ${ }^{13}$. In Australia, the NSW Mine Safety Advisory Council (MSAC) focuses on industry culture change through the implementation of mine safety plans and the improvement of technical and nontechnical skills at all levels of management. Lost-time injury, a usual metric used to assess progress, is defined as an incidence that causes a fatality, permanent disability, or injury resulting in time loss over one shift or more (Standards Australia, 1990). Table 1 presents the evolution of lost time injury in NSW over the last decade. 
Table 1. Lost time injury frequency rates in the NSW minerals industry (2000 - 2011)

\begin{tabular}{|c|c|c|c|c|}
\hline & Coal & Metalliferous & Extractive & $\begin{array}{c}\text { All NSW } \\
\text { mining }\end{array}$ \\
\hline $2000-2001$ & 33.00 & 17.62 & 6.27 & 23.80 \\
\hline $2001-2002$ & 27.00 & 9.63 & 20.45 & 23.12 \\
\hline $2002-2003$ & 23.00 & 9.68 & 26.54 & 20.52 \\
\hline $2003-2004$ & 22.00 & 6.55 & 30.18 & 17.57 \\
\hline $2004-2005$ & 18.00 & 4.28 & 9.00 & 13.85 \\
\hline $2006-2006$ & 15.20 & 4.55 & 8.30 & 12.46 \\
\hline $2007-2008$ & 16.30 & 5.99 & 6.98 & 13.19 \\
\hline $2008-2009$ & 8.27 & 4.45 & 5.67 & 7.26 \\
\hline $2009-2010$ & 7.13 & 4.35 & 12.11 & 7.57 \\
\hline $2010-2011$ & 5.83 & 2.54 & 11.10 & 6.88 \\
\hline & & & & 5.46 \\
\hline
\end{tabular}

The main objective of this study is to analyse and evaluate the impact of IVR-based training on transforming the organisation into HRO through mining safety, management, and planning processes. In other words, we aim to evaluate the quality of the 'training transfer' which we believe play crucial role in developing HRO.

\section{Conceptual Framework}

Wyk and Villiers" define IVR-based training environments as "real-time computer simulations of the real world, in which visual realism, object behaviour, and user interaction are essential elements". The use of IVR-based training environments assumes that Human-Machine interaction stimulates learning processes through better experiencing and improved memorization, leading to a more effective transfer of the learning outcomes into workplace environments. As stated by Meadows ${ }^{22}$ : "When I hear, I forget; when I see, I remember; when I do, I understand". Fulton and colleagues ${ }^{23}$ argue that interactive models like flight simulators are designed to improve trainee's understanding of the consequences of decisional queues under limited resource availability (material, time, or energy) and uncertain or hazardous conditions (unintended consequences). The more realistic the experience is, the stronger the learning process. In situations where real life training opportunities are limited, hazardous or impossible, like emergency responses, virtual reality simulators offer the opportunity to emulate many wideranging experiments ${ }^{24}$.

A crucial condition for IVR technology to deliver satisfying training transfer is its ability to reproduce faithfully not only the physical environment but also functional features of the simulated operations. In the case of flight simulators, Hays and colleagues ${ }^{25}$ demonstrated that the quality of training transfer is highly correlated to the level of fidelity of the simulated environment to the real world. Orlansky and String ${ }^{9}$ argue that the effectiveness of IVR-based training is influenced by (1) the type of simulator in use, (2) the level of experience of participants, and (3) the quality of scenario design and delivery.

A successful mining training program, being IVR-based or not, should result in the creation of a safer workplace ('the mine') and a more competent workforce ('the miners'), contributing to a more effective management of field operations. In turn, improved management will have 
significant and durable impact upon higher industry objectives like sustainable production, corporate profitability, and social responsibility (Figure 1).

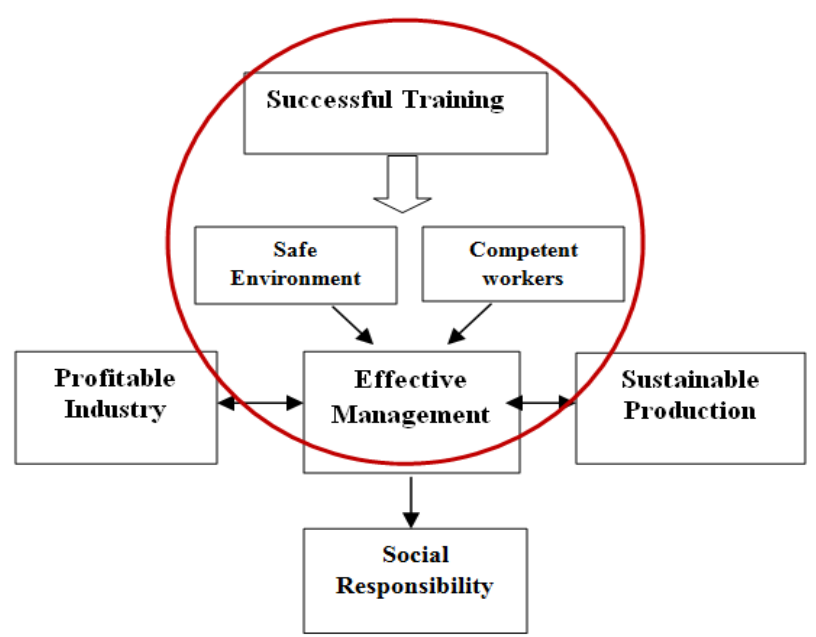

Figure 1. Potential impact of IVR-based training on various aspects of mining operations

\section{A. A more competent workforce}

Most of the time, incidents result from human errors or uncontrolled situations. In a workplace context, a human error is defined as an action, intentional or not, having a negative impact on safety or productivity. This definition covers a large range of circumstances like tripping over, slipping, bending a rule, violating a procedure, or having a lapse of concentration (Figure 2).

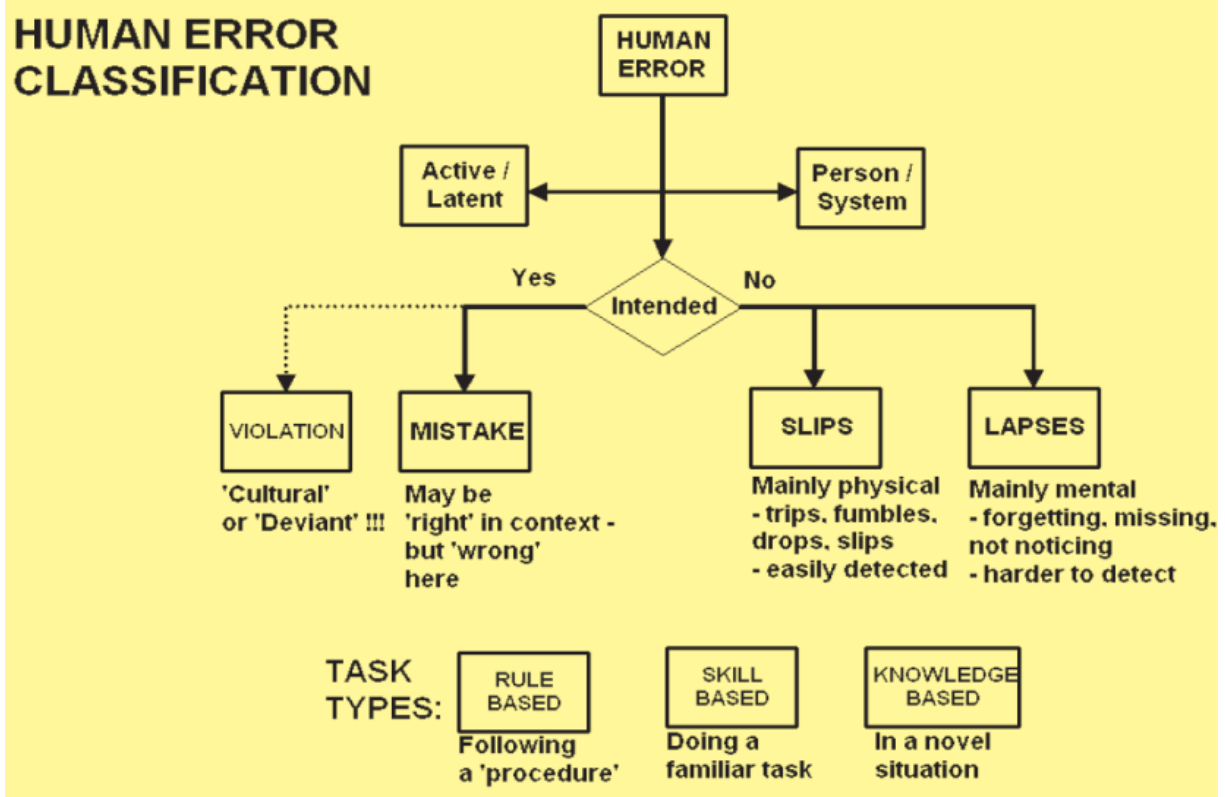

Figure 2. Human Error Classification (source: TIRE, 2013) 
The assumption behind the development of IVR-based training for the mining industry is that it will produce more aware and better prepared workers, at a competitive cost, compared with more traditional approaches. In a context where real world training is whether too dangerous or too demanding on production, investing in virtual reality technology seems to be a reasonable choice $^{26}$. Drawing from the flight simulator paradigm 9 , mining simulators are designed to accelerate a worker's learning curve in a realistic but safe environment through repeated experiments. Causal queues and repetitions are meant to stimulate individual experiences and to enrich corresponding mental models. Ultimately, this learning in context should limit the number of human errors to a tolerable level as skill sets dramatically improve ${ }^{12}$.

\section{B. A safer workplace}

Salzman and colleagues ${ }^{6}$ argue that IVR-based training can support a second-order learning process through which designers, trainers, and managers gain insight into interactions between workers and their environment. Analysing training scenarios, trainee's performance and feedback after the session could lead to better workplace conditions by modifying features of the current environment. Henceforth, mining simulators could become platforms for testing and implementing new ideas developed by engineers or managers with immediate (and safe) response from the workforce. To our knowledge, the use of IVR-based simulations to improve the working environment has not received enough attention yet.

\section{Research Method}

Our case study focuses on a training facility located in Wonoona (NSW) operated by Coal Services Pty Ltd, an Australian service provider. The objective is to evaluate the impact of IVRbased training programs on worker's competences, safety records, and mine productivity. Interviews with trainees, trainers, and managers alongside direct recording of training sessions will constitute our primary data. Secondary data will include records of previous sessions and industry assessment documents. Qualitative and quantitative analyses will be performed to evaluate the level of knowledge transfer and aptitudes to perform in a real environment. Then, a cost-benefit analysis will be used to evaluate the added-value of virtual reality-based on technological and operational costs weighed against overall productivity of the mine being negatively affected by any safety issue.

\section{A. Qualitative Analysis}

Assessing the quality of a training transfer involves three components: 1) Inputs including trainees 2) Outputs including learning and performance, and 3) Training conditions including the environment. According to Salzman et al. ${ }^{6}$, there is a strong relationship between IVR features, individual characteristics, and the IVR-based learning experience. In order to estimate the strength of this relationship across various groups of trainees and training scenarios, we will gather evidence at different stages:

\section{1) Before Training}

The focus will be on trainees' characteristics and their competency and knowledge level prior attending the training sessions. The tools to collect these primary data will include individual questionnaires, interviews with managers and performance sheets. Whenever applicable, we will 
also ask trainees to draw causal loops diagrams of hypothetical scenarios before attending the session.

2) During Training

Aside from the electronic recording of training sessions by the Facility, we will conduct direct observations of individual and collective response to stimuli at specific stop points. These observations will include body language, oral communication between trainees or collective organisation during an exercise. The aim is to evaluate the learning experience.

3) After Training

At the end of a session, individual questionnaires and interviews will be used to record feedback from trainees and trainers. This material will be used to analyse individual responses to an IVR environment and to evaluate the quality of the training transfer in terms of competency. We will also attend debriefing sessions between trainees and trainers. Whenever applicable trainees will be asked to create a second causal loop of hypothetical scenarios in order to compare them with the initial ones.

\section{B. Quantitative Analysis (Cost-Benefit Analysis)}

Based on Yamnill and McLean ${ }^{27}$, training is pointless if it cannot be expressed through a performance measurement. Training should focus on performance and not only on learning. Whenever training can demonstrate a subsequent gain in performance then the training transfer is positive. Conversely in the absence of any gain in performance, the training transfer is negative ${ }^{27}$. Wehrmann et al. ${ }^{28}$ argue that a key point to assess the benefits of a training program is to evaluate its impact directly onto workplace performance. In this case, we propose to adapt the approach proposed by Micheli $^{29}$ to measure the quality of training transfer for flight simulators. This approach includes two indicators: (1) the Performance Enhancement Measurement (PEM) and (2) the Effectiveness for Training Purposes (EfTP).

\section{Performance Enhancement Measurement}

PEM represents the amount of time saved to finish a task due to the IVR-based training sessions. It can also represent the enhancement in performance of employees after attending the training sessions. In this equation:

$\mathrm{Y}_{\mathrm{c}}$ : Indicates the number of hours required by the employee to finish a certain task without attending the training sessions in IVR environment.

$\mathrm{Y}_{\mathrm{x}}$ : indicates the number of hours required by the employee to finish the same task after attending the training sessions in IVR environments.

$$
\text { Percent Saving }=\frac{Y c-Y x}{Y c} \times 100(1)
$$

The greater the number the higher is the savings. Values for Yc and Yx will be derived from interviews with trainees and different levels of management.

\section{Effectiveness for Training Purposes}

TE ratio indicates the amount of time saved compared to the amount of time spent in the simulator:

$$
\text { Transfer effectiveness ratio }=\frac{\text { Number of training unit in simulator }}{\text { Number of unit in the Mine for equivalent training }}
$$


The greater the number the better is the training transfer. If trainee received 50 hours of training in IVR environment and in return he/she can finish the task in 30 hours (Transfer effectiveness ratio $-\mathrm{TER}=1.6$ ) compare to the time before attending the training session in IVR environment and receiving different trainings for instance if it took him/her 40 hours $(\mathrm{TER}=1.2)$ then the transfer effectiveness of IVR environment is 1.6 compare to 1.4. Figures associated with number of hours to perform a task will be derived from interviews with trainees and different levels of management.

Using PEM and EfTP indicators to assess potential benefits, we will use a costing model to conduct our cost-benefit analysis. For example, Rai and Wong ${ }^{30}$ suggest that a flight simulator costs only $15 \%$ of using actual helicopters for training purposes. Drawing from their study, we have selected the following cost categories:

- Costs associated with designing and developing a simulator.

- Costs associated with operating an IVR-based training session.

- Specific technology costs (Curve screen, Domes, 360 degree theatre).

\section{Conclusion}

This paper presented the research framework to quantitatively and qualitatively evaluate the effect of IVR-based training on training transfer in the mining industry. Two main components of effective management have been identified as a competent workforce and a safe workplace. Our evaluation framework will be applied to an IVR-based training facility operated by Coal Services Pty Ltd in Wonoona (NSW, Australia). Our methodology aims to collect a broad range of performance, behavioural,, and attitudinal data to help with a qualitative and quantitative analysis of the impact of mining simulators on improving workforce's performance and workplace's safety records. These data, associated with cost estimates, will provide a reasonable basis for conducting a cost-benefit analysis that will provide the industry with an evidence-based outcome to examine its future investments in this technology.

\section{References}

${ }^{1}$ Bell, P. C., "Visual interactive modelling: The past, the present, and the prospects", European Journal of Operational Research, Vol. 54, No. 3, 1991, pp. 274-286. http://dx.doi.org/10.1016/0377-2217(91)90101-Z

${ }^{2}$ Rickel, J., and Johnson, W. L., "STEVE (video session): a pedagogical agent for virtual reality", Proceedings of the second international conference on Autonomous agents, ACM, 1998.

${ }^{3}$ Furlong, T. J., Vance, J. M., et al., "Spherical mechanism synthesis in virtual reality", Transactions-American Society Of Mechanical Engineers Journal Of Mechanical Design, Vol.121, No. 4, 1999, pp. 515-520.

${ }^{4}$ Burdea, G., and Coiffet, P., "Virtual reality technology", Presence: Teleoperators \& Virtual Environments, Vol. 12, No. 6, 2003, pp. 663-664.

http://dx.doi.org/10.1162/105474603322955950 
${ }^{5}$ Fox, J., Arena, D., et al., "Virtual reality", Journal of Media Psychology: Theories, Methods, and Applications, Vol. 21, No. 3, 2009, pp. 95-113. http://dx.doi.org/10.1027/1864-1105.21.3.95

${ }^{6}$ Salzman, M. C., Dede, C. et al., "A Model for Understanding How Virtual Reality Aids Complex Conceptual Learning", Presence: Teleoperators \& Virtual Environments, Vol. 8, No. 3, 1999, pp. 293-316. http://dx.doi.org/10.1162/105474699566242

${ }^{7}$ Moreno, R., and Mayer, R. E., "Learning science in virtual reality multimedia environments: Role of methods and media", Journal of Educational Psychology, Vol. 94, No.3, 2002, pp. 598-610. http://dx.doi.org/10.1037/0022-0663.94.3.598

${ }^{8}$ Moreno, R., and Mayer, R., "Interactive multimodal learning environments", Educational Psychology Review, Vol. 19, No. 3, 2007, pp. 309-326. http://dx.doi.org/10.1007/s10648$\underline{007-9047-2}$

${ }^{9}$ Orlansky, J., and String, J., "Cost-Effectiveness of Flight Simulators for Military Training. Volume 1", Use and Effectiveness of Flight Simulators, DTIC Document, 1977.

${ }^{10}$ Bakken, B., Gould, J., et al., "Experimentation in learning organizations: A management flight simulator approach", European Journal of Operational Research, Vol. 59, No. 1, 1992, pp. 167-182. http://dx.doi.org/10.1016/0377-2217(92)90013-Y

${ }^{11}$ Filigenzi, M. T., Orr, T. J., et al., "Virtual reality for mine safety training", Applied occupational and environmental hygiene, Vol. 15, No.6, 2000, pp. 465-469. http://dx.doi.org/10.1080/104732200301232

${ }^{12}$ Deaton, J. E., Barba, C., et al., "Virtual environment cultural training for operational readiness (VECTOR)", Virtual Reality, Vol. 8, No. 3, 2005, pp. 156-167. http://dx.doi.org/10.1007/s10055-004-0145-X

${ }^{13}$ Van W., E. and De Villiers, R., "Virtual reality training applications for the mining industry", Proceedings of the 6th international conference on computer graphics, virtual reality, visualisation and interaction in Africa, ACM, 2009.

${ }^{14}$ Schmitt, P. J., Agarwal, N. et al., "From planes to brains: Parallels between military development of virtual reality environments and virtual neurological surgery", World Neurosurgery, Vol. 78, No. 3-4, 2012, pp. 214-219. http://dx.doi.org/10.1016/j.wneu.2012.06.014

${ }^{15}$ Perrow, C., Normal accidents: Living with high-risk technologies, New York: Basic Books, 1984.

${ }^{16}$ Leveson, N., Dulac, N., et al., "Moving beyond normal accidents and high reliability organisations: A systems approach to safety in complex systems", Organization Studies, 30, 2009, pp. 227-249. http://dx.doi.org/10.1177/0170840608101478

${ }^{17}$ Hopkins, A., "The limits of normal accident theory", Safety Science, Vol. 32, 1999, pp. 93-102.

${ }^{18}$ Roberts, K., "Some characteristics of one type of high re liability organisation", Organization Science, Vol. 1, No. 2, 1990, pp. 160-176. http://dx.doi.org/10.1287/orsc.1.2.160

${ }^{19}$ La Porte, T., and Consolini, P., "Theoretical and operational challenges of 'high reliability organisations': air traffic control and aircraft carriers", International Journal of Public Administration, Vol. 21, No. 6-8, 1998, pp. 847-852. http://dx.doi.org/10.1080/01900699808525320

${ }^{20} \mathrm{Kizil,} \mathrm{M.,} \mathrm{"Virtual} \mathrm{reality} \mathrm{applications} \mathrm{in} \mathrm{the} \mathrm{Australian} \mathrm{minerals} \mathrm{industry",} \mathrm{Application} \mathrm{of}$ Computers and Operations Research in the Minerals Industries, South African, 2003, pp. 569-574. 
International Symposium for Next Generation Infrastructure October 1-4, 2013, Wollongong, Australia

${ }^{21}$ van Wyk, E. and R. de Villiers, "Virtual reality training applications for the mining industry", Proceedings of the 6th international conference on computer graphics, virtual reality, visualisation and interaction in Africa, ACM, 2009.

${ }^{22}$ Meadows, D. L., "Tools for understanding the limits to growth: comparing a simulation and a game", Simulation \& Gaming, Vol. 32, No. 4, 2001, pp. 522-536. http://dx.doi.org/10.1177/104687810103200408

${ }^{23}$ Fulton, E. A., Jones, T., et al., "A multi-model approach to stakeholder engagement in complex environmental problems", International Congress on Modelling and Simulation (MODSIM 2011), Perth, WA, 2011.

${ }^{24}$ Seymour, N. E., Gallagher, A. G. et al., "Virtual reality training improves operating room performance: results of a randomized, double-blinded study", Annals of Surgery, Vol. 236, No. 4, 2002, p. 458. http://dx.doi.org/10.1097/00000658-200210000-00008

${ }^{25}$ Hays, R. T., Jacobs, J. W., et al., "Flight simulator training effectiveness: A meta-analysis.", Military Psychology, Vol.4, No. 2, 1992, pp. 63-74. http://dx.doi.org/10.1207/s15327876mp0402_1

${ }^{26} \mathrm{Kral}$, S., "Improved training reduces worker injuries", Mining Engineering, Vol. 54, No. 10, 2002, pp. 23-26.

${ }^{27}$ Yamnill, S., and McLean, G. N., "Theories supporting transfer of training", Human Resource Development Quarterly, Vol. 12, No.2, 2001, pp. 195-208. http://dx.doi.org/10.1002/hrdq.7

${ }^{28}$ Wehrmann, K. C., Shin, H. et al., "Transfer of Training", Journal of Health \& Social Policy, Vol. 15, No. 3-4, 2003, pp. 23-37. http://dx.doi.org/10.1300/J045v15n03_03

${ }^{29}$ Micheli, G. S., Analysis of the transfer of training, substitution and fidelity of simulation of training equipment, US Army reports, 1972.

${ }^{30}$ Rai, S., and K. Wong, "The use of interactive simulations to affect driving behaviour", Proceedings of the $3^{\text {rd }}$ Annual International Conference on Computer Games, Multimedia and Allied Technology, CGAT, 2010. 